\title{
Correlation between Serum hs-CRP and Magnesium Ion with Osteocalcin in Acute Leukemia Patients
}

\author{
Nuniek Luthy Naftali, MI. Diah Pramudianti, Yuwono Hadisuparto
}

Department of Clinical Pathology, Faculty of Medicine, Sebelas Maret University/Dr. Moewardi Hospital, Surakarta, Indonesia. E-mail: luthy07@yahoo.com

\begin{abstract}
Acute leukemia is a proliferation of immature cells in the bone marrow that affects peripheral blood or other organs. Inflammation has a vital role in cancer pathophysiology. Inflammation in leukemia occurs through two mechanisms: intrinsic and extrinsic. Magnesium deficiency leads to inflammation in acute leukemia patients. Manifestation of inflammation in acute leukemia are abnormalities in musculoskeletal systems such as osteopenia, osteoporosis, osteonecrosis, and pathological fractures. Increased inflammation in the bone remodeling process increases osteoclast (OC) regulation and decreases osteoblast $(\mathrm{OB})$ activity resulting in reduced osteocalcin (OCN) production. Osteocalcin, also known as gamma-carboxy glutamic acid-containing protein or bone Gla-protein, is a small, non-collagen protein associated with the bone matrix. Osteocalcin is known as bone formation. This study aimed to analyze the correlation between hs-CRP, ion Mg and serum OCN levels in acute leukemia. A cross-sectional observational analytic study in acute leukemia subjects was conducted at Clinical Pathology Installation of Dr. Moewardi Hospital. Surakarta from August to September 2020. Normality test of Shapiro-Wilk was used to determine data distribution, Pearson correlation test was used to analyze the correlation strength between variables. From a total of 35 subjects, there was a significant negative correlation between hs-CRP and serum OCN in acute leukemia ( $r=-0.46 ; p=0.06)$, but no correlation was found between $\mathrm{Mg}$ ion and serum OCN in acute leukemia patients $(r=0.09 ; p=0.957)$. The mean of hs-CRP, Mg ion, and OCN was $2.95 \pm 4.95 \mathrm{mg} / \mathrm{dL}, 0.49 \pm 0.05 \mathrm{mmol} / \mathrm{L}$, and $16.32 \pm 19.46 \mathrm{ng} / \mathrm{mL}$, respectively. Advanced research with chronic leukemia population and other variants as needed.
\end{abstract}

Keywords: Acute leukemia, C-reactive protein, osteocalcin, ion magnesium

\section{INTRODUCTION}

Leukemia is one of the most common malignant diseases affecting the world population. Globally, in 2018, leukemia ranked as the fifteenth most common cancer with 309,006 mortalities. Data from the World Health Organization (WHO) in 2018 showed that the most cases were found in East Asia with 101,285 new cases and 78,805 deaths, while the number of hematopoietic malignancies in Indonesia reached $6 \%$ to $8 \%$ of the total new malignancies per year. Leukemia triggers inflammation through two mechanisms; such as intrinsic and extrinsic. ${ }^{1-3}$

Increased transcription of NFkB in acute leukemia triggers an increase in proinflammatory cytokines and an increase in hs-CRP. Mg ion deficiency in acute leukemia can be caused by inadequate intake, diarrhea, anorexia due to chemotherapy, and tubular dysfunction. Lack of $\mathrm{Mg}$ ions can trigger inflammation in acute leukemia patients due to an increase in Ca ion exchange ( $\mathrm{Mg}$ is a competitive ion with $\mathrm{Ca}$ ions), and the accumulation of intracellular
$\mathrm{Ca}$ ions increases the risk of inflammation by activating NFkB transcription. ${ }^{1-3}$

Interleukin (IL) $1 \beta, \mathrm{IL}-6, \mathrm{IL}-10$, and Tumor Necrosis Factor (TNFa), inflammatory proteins, and enzymes are several stimuli that activate inflammation and induce the production of inflammatory cytokines. Inflammatory proteins in the blood include C-Reactive Protein (CRP), haptoglobin, serum amyloid A, fibrinogen, and alpha 1-acid glycoprotein. C-reactive protein is an acute-phase protein, synthesized mainly by the liver based on IL-1 $\beta$ and IL- 6 stimuli. The CRP test can be replaced with a High Sensitivity C-Reactive Protein (hs-CRP) test because the hs-CRP test is more sensitive than the CRP test. Inflammation in leukemia is caused by a decrease/deficiency of $\mathrm{Mg}$ ions due to diarrhea, chemotherapy, and reduced intake. ${ }^{4-7}$

Inflammation in acute leukemia can cause a high risk of fracture, osteopenia, osteoporosis, and osteonecrosis. Osteocalcin (OCN) is a non-collagen protein, which has a close relationship with bone metabolism. Osteocalcin is produced by osteoblasts 
$(\mathrm{OB})$, which is known as a biomarker of bone formation. Leukemic cells inhibit $O B$ and bone formation by destroying messenger ribonucleic acid (mRNA) OCN in CD45-bone marrow. ${ }^{7.8}$

Inflammation that occurs in acute leukemia can cause many complications, including disorders of the musculoskeletal system. Research by Yang et al. found a positive correlation between CRP levels and bone lesions with a value of $r=0.6096$. In addition, CRP levels were positively correlated with levels of Receptor Activator of Nuclear Factor Kappa-Beta Ligand (RANKL). Research Atkinson et al. found a correlation between OCN and $\mathrm{Mg}$ in acute leukemia patients with a value of $r=0.54$. The oral administration of $\mathrm{Mg}$ can normalize serum $\mathrm{Mg}$ values and serum OCN levels. However, in Indonesia, there has been no research that determines the correlation between serum OCN levels and inflammatory markers of CRP and $\mathrm{Mg}{ }^{9}$

This research was expected to provide information on the importance of serum hs-CRP and $\mathrm{Mg}$ ions as a screening to determine the inflammatory process that can cause musculoskeletal system abnormalities in acute leukemia patients and can be used as an alternative to serum OCN measurement in terms of economics and laboratory capabilities.

\section{METHODS}

This study was an observational analytic study with a cross-sectional approach to determine the correlation between levels of hs-CRP, Mg ion, and serum OCN in acute leukemia patients. The research was conducted at the Clinical Pathology Installation of the Regional General Hospital Dr. Moewardi in Surakarta from August to September 2020. The study's target population was patients with acute leukemia (AML and ALL) diagnosed based on the results of Bone Marrow Puncture (BMP) and/or immunophenotyping at the Clinical Pathology Installation of Dr. Moewardi Hospital from August 2020 to September 2020. Classification of acute leukemia in this study was based on the French-American British Cooperative Group (FAB), using a limit of the number of immature cells (blast cells) in the bone marrow of $30 \%$. Patients were taken blood samples for measurement of hs-CRP, Mg ion, and serum OCN. During 2 months, 35 patients with acute leukemia who met the inclusion and exclusion criteria of the study were found. The estimated sample size based on the sample size formula for the correlative analysis research design was as follows:

$$
\begin{aligned}
& N=\left\{\frac{Z \alpha+Z \beta}{0.5 \ln [(1+r) /(1-r)]}\right\}^{2}+3 \\
& \text { Za: alpha standard deviation } \\
& \text { Z } \beta \text { : beta standard deviation } \\
& \quad \text { r: correlation }
\end{aligned}
$$

Type 1 error $5 \%$ oneway hypothesis, Za 1.64 with $95 \%$ confidence level. Type 2 error $10 \%, Z \beta$ 1.28. A study by Fatahi et al. found a correlation between $\mathrm{OCN}$ and $\mathrm{Mg}$ with $\mathrm{r}=0.475$. Therefore, the authors set a correlation value of 0.475 . By entering this value into the sample size formula, a minimum sample size of 30 people was obtained. Inclusion criteria in this study were as follows: New acute leukemia patients (AML and ALL) diagnosed based on the results of BMP interpretation and/or immunophenotyping issued by a Clinical Pathologist Specialist at Dr. Moewardi Hospital, children and adults, male and female who agreed to participate in the study by signing informed consent. Exclusion criteria in this study were as follows: history of liver disease \{(Serum Glutamic Pyruvic Transaminase (SGPT) > $102 \mathrm{U} / \mathrm{L}$ )\} obtained from data in medical records, pregnancy and lactation based on anamnesis, bone abnormalities and pathological fractures obtained from the anamnesis, no widespread inflammation found from physical examination, no electrolyte disturbances and kidney disorders found from laboratory results.

Subjects were selected consecutively, whereas the patient's identity and medical history were collected when filling informed consent at the Clinical Pathology Laboratory Installation. This study received the approval of the biomedical research ethics committee at the Dr. Moewardi Hospital and the patient's consent. A total of $3 \mathrm{~mL}$ venous blood was taken with a tube without anticoagulant/with a gel separator to measure serum levels of hs-CRP, Mg ions, and OCN. Blood samples without anticoagulant/with gel separator were centrifuged for 10-15 minutes at a speed of 5000-6000 rpm. The serum formed was separated and put into an aliquot. Serum samples were stored in a refrigerator at -80 C until sample analysis was carried out. hs-CRP levels were measured in this study using the SEKISUI reagent kit from The SEKISUI Chemical Co.Ltd USA and the control reagent kit of Proline Trulab CRP hs level $1 . \mathrm{Mg}$ ions were measured in this study using a reagent kit from Nova Biomedical $8+$ with an 
ion-selective electrode method. (ISE). OCN levels were measured in this study using a reagent kit from Elecsys N-MID OCN Roche diagnostic. The reagent control kit of PreciControl Varia was also used. Serum OCN levels were measured in this study using the sandwich Electrochemiluminescence Immunoassay (ECLIA) method.

This study has received approval from the Health Research Ethics Committee of the Dr. Moewardi Hospital, Surakarta, with number No: 962/V11/HREC/2020.

\section{RESULTS AND DISCUSSIONS}

This study involved 35 subjects with acute leukemia who were diagnosed based on BMP and/or immunophenotyping results by a Clinical Pathologist Specialist at the Clinical Pathology Installation of the Dr. Moewardi Hospital. Table 1 showed that the total research subjects in this study consisted of 14 (40\%) female patients and 21 (60\%) male patients. The overall patient age ranged from a median of 9 (3-67) years. The patient's general

Table 1. Characteristics of research subjects

\begin{tabular}{|c|c|c|c|}
\hline Parameter & Total & Mean \pm SD & Median (min-max) \\
\hline Age (years) ** & & & $9(3-67)$ \\
\hline \multicolumn{4}{|l|}{ Gender (\%) } \\
\hline Male & $60(\%)$ & & \\
\hline Female & $40(\%)$ & & \\
\hline \multicolumn{4}{|l|}{ Diagnosis (\%) } \\
\hline $\mathrm{AML}$ & 40 (\%) & & \\
\hline ALL & $60(\%)$ & & \\
\hline $\mathrm{Hb}(\mathrm{g} / \mathrm{dL}) *$ & & $8.97 \pm 0.85$ & \\
\hline Leukocyte $\left(10^{3} / \mu \mathrm{L}\right) * *$ & & & $18.7(11.6-33.1)$ \\
\hline Platelet $\left(10^{3} / \mu \mathrm{L}\right)$ * & & $90.63 \pm 21.36$ & \\
\hline $\mathrm{SGPT}(\mathrm{U} / \mathrm{L}) *$ & & $33.83 \pm 10.39$ & \\
\hline Creatinine $(\mathrm{mg} / \mathrm{dL}) * *$ & & & $0.9(0.6-1.1)$ \\
\hline Sodium $(\mathrm{mmol} / \mathrm{L}) * *$ & & & $138.7(124.2-149)$ \\
\hline Potassium (mmol/L) * & & $3.74 \pm 0.54$ & \\
\hline Calcium ion $(\mathrm{mmol} / \mathrm{L}) * *$ & & & $1.03(0.5-1.3)$ \\
\hline
\end{tabular}

Note: AML: Acute Myeloid Leukemia; ALL: Acute Lymphoblastic Leukemia; Hb: Hemoglobin; SGPT; Serum Glutamic Pyruvic Transaminase; SD: Standard Deviation; min: minimum; maks: maximum; mg: milligram; mmol/L: millimoles per liter; $\mathrm{ng} / \mathrm{mL}$ : nanogram per milliliter.

*Normal distribution (Mean \pm SD)

${ }^{* *}$ Abnormal distribution [median (min-max)]

Table 2. Characteristics of research variable

\begin{tabular}{lccc}
\hline Parameter & Mean \pm Total SD & Mean \pm AML SD & Mean \pm ALL SD \\
\hline $\mathrm{hs}-\mathrm{CRP}(\mathrm{mg} / \mathrm{dL})$ & $2.95 \pm 4.95$ & $3.12 \pm 5.88$ & $2.84 \pm 4.38$ \\
Ion $\mathrm{Mg}(\mathrm{mmol} / \mathrm{L})$ & $0.49 \pm 0.05$ & $0.51 \pm 0.41$ & $0.49 \pm 0.54$ \\
$\mathrm{OCN}(\mathrm{ng} / \mathrm{mL})$ & $16.32 \pm 19.46$ & $16.84 \pm 23.96$ & $15.54 \pm 16.72$ \\
\hline
\end{tabular}


Correlation analysis was carried out to determine the strength of the correlation between serum levels of hs-CRP, Mg ion, and OCN in the total acute leukemia population. The distribution of serum $\mathrm{Mg}$ ion data in this study was normally distributed, while the distribution of serum hs-CRP and OCN data in this study was not normally distributed. The distribution of hs-CRP and serum OCN data in this study was normally distributed after data transformation was carried out to normalize the data distribution. ${ }^{10}$

The results of the correlation test showed a negative correlation with moderate and significant strength between serum levels of hs-CRP and OCN in the acute leukemia population $(r=-0.46 ; p=0.006)$; however, there was no significant correlation between serum levels of $\mathrm{Mg}$ ions and $\mathrm{OCN}$ in the acute leukemia population $(r=0.09, p=0.957)$. The results of the Pearson correlation test of research variables in the acute leukemia population can be seen in Table 3.

Table 3. Results of Pearson correlation test for each research variable

\begin{tabular}{lcc}
\hline & \multicolumn{2}{c}{ OCN $^{*}$} \\
\cline { 2 - 3 } & $\mathrm{r}$ & $\mathrm{p}$ \\
\hline hs-CRP * & -0.46 & $0.006^{* *}$ \\
Ion Mg & 0.09 & 0.957 \\
\hline
\end{tabular}

Data on the basic characteristics of the subjects in this study showed the age of all patients with a median of 9 (3-67) years. This study was following the research of Ahmad et al., which found the prevalence of acute leukemia of $38 \%, 17.5 \%, 15 \%, 9 \%, 8.5 \%$, $25 \%$, and $3.75 \%$ at the age range of $0-10$ years, $11-20$ years, 21-30 years, 31-40 years, $41-50$ years, $51-60$ years, and $61-70$ years. ${ }^{11}$

The data on the essential characteristics of the research subjects showed that the subjects in this study consisted of $60 \%$ male and $40 \%$ female. The results of this study were following data from the American Cancer Society, which found that the incidence of acute leukemia is more common in males than females. In addition, research by Ahmad et al. found the prevalence of acute leukemia of $64.5 \%$ and $35.5 \%$ in males and females, respectively. ${ }^{11,12}$

Acute lymphoid leukemia in this study was found in $60 \%$ of subjects, and AML was found in $40 \%$ of subjects. The results of this study were in accordance with previous research by Ahmad et al., which saw the most diagnoses of ALL (49.5\%) followed by AML (31.25\%). Ahmad et al. stated that the high incidence of ALL was because the most acute leukemia survivors with a diagnosis of ALL. ${ }^{11}$

The data on the essential characteristics of the research subjects showed $\mathrm{Hb}$ levels with an average of $8.97 \pm 0.85 \mathrm{~g} / \mathrm{dL}$. The results of this study were not in accordance with the research of Liem et al., which stated that the majority of $\mathrm{Hb}$ levels in acute leukemia patients were $<7 \mathrm{~g} / \mathrm{dL}$ at the time of diagnosis. Anemia in leukemia occurs because of the suppression by the leukemia cells against normal blood cells in the bone marrow. ${ }^{13,14}$

The median of leukocytes count of 18.7 (11.6-33.1) $10^{3} / \mu \mathrm{L}$ was found in this study. Leukocytosis in acute leukemia is in accordance with the results of Perez et al., who found leukocyte levels $>14.510^{3} / \mu \mathrm{L}$ in $36.6 \%$ of the study population. ${ }^{15}$

The mean platelets count in this study was $90.63 \pm 21.3610^{3} / \mu \mathrm{L}$. These results were in accordance with the research of Perez et al., which obtained a platelet level of $15010^{3} / \mu \mathrm{L}$. Thrombocytopenia is one of the symptoms in acute leukemia associated with a poor prognosis due to bleeding that occurs. ${ }^{15}$

The mean of SGPT levels in this study was $33.83 \pm 10.39 \mathrm{U} / \mathrm{L}$. These results followed the research of El-Shafey et al., which found SGPT levels of 21-39 U/L in acute leukemia patients before chemotherapy. The value will increase during the chemotherapy process with SGPT levels of 25-61 U/L. However, the results of this study were not following the research of Abdalla and Akasha, which found an increased SGPT level in acute leukemia patients with levels of $85.1 \pm 34.8 \mathrm{U} / \mathrm{L} .{ }^{16,17}$

Kidney function in this study was observed in the creatinine test with a median of $0.9(0.6-1.1) \mathrm{mg} / \mathrm{dL}$. The results of this study were not in accordance with the study of Salman et al., which found an increase in serum creatinine in acute leukemia patients with levels of $1.3 \pm 0.9 \mathrm{mg} / \mathrm{dL}$. Contrastingly, a study by Tamil found normal serum creatinine levels in $53 \%$ of the study population. ${ }^{18,19}$

The median sodium and calcium ion levels in this study were 138.7 (124.2-149) $\mathrm{mmol} / \mathrm{L}$ and 1.03 $(0.5-1.3) \mathrm{mmol} / \mathrm{L}$, respectively, while the mean of potassium levels was $3.74 \pm 0.54 \mathrm{mmol} / \mathrm{L}$. The results of this study were following the research of Sallman et al., which found the sodium ions of $137 \pm 7.9$ $\mathrm{mmol} / \mathrm{L}$, potassium ions of $3.92 \pm 0.76 \mathrm{mmol} / \mathrm{L}$, and calcium ions of $1.94 \pm 0.4 \mathrm{mmol} / \mathrm{L}$ in the acute leukemia population before receiving chemotherapy. ${ }^{18}$

There was a negative correlation between serum hs-CRP and OCN with moderate and significant strength in all acute leukemia patients $(r=-0.46$; $p=0.006$ ). Previous research by Gu et al. showed the 
correlation between hs-CRP and OCN with an r-value of -0.475 in the overweight male population compared to obese. The correlation between serum hs-CRP levels and OCN in acute leukemia can occur due to two processes, extrinsic mechanisms involving immunity and microenvironment factors, and intrinsic mechanisms include genetic disorders and tumor suppression of oncogenes that activate inflammatory pathways. The mutation process in leukemia will trigger an increase in the binding of the chemokine CXCL12 to its receptor CXCR4 and trigger the activation of NFkB. Increased activity of NFkB induces the production of proinflammatory cytokines. C-reactive protein is produced by hepatocytes based on the stimulus of proinflammatory cytokines and increases during the inflammatory process. Inflammation affects the bone remodeling process by increasing bone resorption by increasing osteoclastogenesis and increasing the expression of RANKL and RANK. In acute leukemia, an increase in NFB transcription triggers an increase in proinflammatory cytokines and hs-CRP. An increase in the proinflammatory cytokines make an essential contribution to bone loss by promoting bone resorption and impairing bone formation. ${ }^{6,20,21}$

Correlation analysis in this study found no correlation ( $r=0.09 ; p=0.957)$ between serum $\mathrm{Mg}$ ions and OCN. The results of this study were in accordance with the study of Salman et al., which found no significant difference between $\mathrm{Mg}$ ion levels before and after chemotherapy in acute leukemia patients. ${ }^{18} \mathrm{Mg}$ ion levels in the body are very dependent on intake. The human body will respond to $\mathrm{Mg}$ ion hemostasis when there is a change in $\mathrm{Mg}$ ion intake, thereby making it difficult to evaluate the hypomagnesia condition in each individual. ${ }^{21}$

Analysis of $\mathrm{Mg}$ and $\mathrm{OCN}$ ion levels is needed in acute leukemia patients to screen the severity of inflammation that can cause musculoskeletal system disorders in acute leukemia patients. ${ }^{22}$

No differentiation of serum OCN based on age and no differentiation of diagnosis of acute leukemia were limitations in this study.

\section{CONCLUSIONS AND SUGGESTIONS}

It was concluded that there was a significant negative correlation with moderate strength between serum levels of hs-CRP and OCN in acute leukemia patients $(r=-0.46 ; p=0.006)$, but no correlation was found between serum levels of $\mathrm{Mg}$ ions and OCN in acute leukemia patients $(r=0.09$; $\mathrm{p}=0.957)$.

Therefore, further research was needed to determine the correlation between serum hs-CRP levels and OCN in the acute leukemia population using different study designs such as case-control or cohorts and studies in chronic leukemia populations.

\section{REFERENCES}

1. Tebbi CK. Etiology of acute leukemia: A review. Cancers, 2021; 13: 2256.

2. Yaswir R, Wahid I, Rahmadin B. Profil penderita leukemia mieloblastik akut di bagian penyakit dalam RSUP Dr. M. Djamil Padang. Jurnal Kesehatan Andalas, 2017; 6(3): 495-501.

3. Bray F, Ferlay J, Soerjomataram I, Siegel RL, Torre LA, et al. Global cancer statistics 2018: GLOBOCAN estimated of incidence and mortality worldwide for 36 cancers in 185 countries. CA Cancer J Clin, 2018; 68: 394-424.

4. Chen L, Deng $H$, Cui $H$, Fang J, Zuo $Z$, et al. Inflammatory responses and inflammation-associated diseases in organs. Oncotarget, 2018; 6(6): 7204-7218.

5. Craver BM, Alaoui KE, Scherber RM, Fleischman AG. The critical role of inflammation in the pathogenesis and progression of myeloid malignancies. Cancers, 2018; 10(4): 104.

6. Sproston NR, Ashworth JJ. Role of C-reactive protein at sites of inflammation and infection. Front. Immunol, 2018; 9: 754.

7. Fatahi S, Ghaidi E, Mousavi SM, Bawadi H, Rahmani J, et al. The association between osteocalcin and C-reactive protein; a relation of bone with inflammation: A systematic review and meta-analysis. Hom Metab Res, 2019; 2019(51): 353-361.

8. Donmez AD, Isik P, Cetinkaya S, Yarali N. Bone loss in pediatric survivors of acute lymphoblastic leukemia. Eurasian J Med, 2019; 51(1): 38-41.

9. Yang J, Liu Z, He J, Yang J, Lin P, et al. C-reactive protein promotes bone destruction in human myeloma through the CD32-p38MAPK twist axis. Sci Signal, 2018; 10(509): 1-21. Available at: https://www.ncbi. nlm.nih.gov/pmc/articles/PMC5827954/pdf/nihms94 4048.pdf (accessed 17 August, 2020).

10. Dahlan MS. Statistik untuk kedokteran dan kesehatan. Epidemiologi Indonesia, Ed VI., Jakarta, Salemba Medika, 2017; 223-244.

11. Ahmad S, Kifayatullah Shah AK, Hussain H, Haq AU, Ullah A, et al. The prevalence of acute leukemia and chronic forms of leukemia in various regions of Khyber Pakhtunkhwa, Pakistan: Needs much more to be done. Bangladesh Journal of Medical Science, 2019; 18(2): 222-227.

12. American Cancer Society. Acute lymphocytic leukemia early detection, diagnosis, and types. 2019. Available at: https://www.cancer.org/content/dam/CRC/ PDF/Public/8671.00.pdf (accessed 17 August, 2020).

13. Liem EF, Mantik M, Rampeang N, Hubungan kadar hemoglobin dan tercapainya remisi pada anak 
penderita leukemia akut. JMR, 2019; 1(3): 1-7.

14. Wang F, Lv H, Zhao B, Zhou L, Wang S, et al. Iron and leukemia: New insights for future treatments. Journal of Experimental \& Clinical Cancer Research, 2019; 38: 406.

15. Perez JCJ, Arellano GG, Garza LH, Rivera LJM, Almaguer DG. Revisiting the complete blood count and clinical findings at diagnosis of childhood acute lymphoblastic leukemia: 10-years experience at a single center. Hematology Transfusion and Cell Therapy, 2018; 41: 47-61.

16. El-Shafey A, Amer SM, Allam MG, El-Alfy MS. Clinical chemistry studies in Egyptian children with acute lymphoid and myeloid leukemia. AASCIT, 2017; 3(2): 10-17.

17. Abdalla AA, Akasha R. Liver enzyme, urea and creatinine among acute lymphocytic leukemia in Sudanese patients. Journal of Medical and Biological
Science Research, 2018; 4(2): 72-75.

18. Salman AF, Ali KF, Alwan AF. Evaluation of electrolytes in adult patients with acute leukemia before and after chemotherapy. Baghdad Science Journal, 2013; 10(2): 2013.

19. Tamsil FF. Analisis kadar kreatinin ada anak dengan leukemia limfoblastik akut di pusat kanker anak Estella BLU RSUP Prof Dr. RD Kandau. ECL, 2014; 2(1): 2014.

20. Gu P, Liu Y, Ding Q. Correlation between osteocalcin and visceral fat area in overweight and obese male population. Int J Clin Exp Med, 2017; 10: 6980-6986.

21. Rao SS, HU Y, Shie PL, Cao J, Wang ZX. Omentin-1 prevents inflammation-induced osteoporosis by downregulating the pro-inflammatory cytokines. Springer Nature, 2018; 6-9.

22. Nielsen FH. Magnesium deficiency and increased inflammation: Current perspectives. Journal of Inflammation Research, 2018; 11: 25-34. 